\title{
An Analytical Solution for Steady Temperature Profiles in a Vertically Stratified Environment
}

\author{
Ahmad. S. Awad ${ }^{1}$ \\ ${ }^{1}$ Department of Mechanical Engineering, Faculty of Engineering Technology, Al-Balqa` Applied University, \\ Amman, Jordan \\ Correspondence: Ahmad. S. Awad, Al-Balqa` Applied University, P. O. Box 330116, Amman 11134, Jordan. \\ E-mail: Ahmadsawwad64@yahoo.com
}

Received: June 5, $2014 \quad$ Accepted: June 11, $2014 \quad$ Online Published: June 30, 2014

doi:10.5539/mas.v8n4p230 URL: http://dx.doi.org/10.5539/mas.v8n4p230

\begin{abstract}
Thermal stratification is an important phenomenon to be evaluated and studied to save energy consumed in fully insulated environments and to improve indoor air quality and human comfort. An analytical study to investigate stratified flow characteristics in a ventilated environment was presented. Most existing studies were either numerical or experimental and correlations for predicting characteristics of stratified flow, such as temperature distribution, temperature gradient, stratified layer thickness and height were based on empirical data. A simple mathematical model was developed to predict these characteristics. The predictions were compared with the published experimental data and good agreement has been obtained. Such a simple model would be very useful to practicing engineers for HVAC and designing applications.
\end{abstract}

Keywords: analytical, empirical, small scale, environmental chamber, fully insulated environment, buoyancy

\section{Introduction}

Ventilation is the approach for reaching the best human comfort. It is used to control temperature, humidity, air quality and the quantity of needed air to replenish oxygen, or remove moisture, smoke, heat, dust, airborne bacteria, and carbon dioxide. Ventilation is used to remove unpleasant smells and excessive moisture, introduce outside air, to keep interior building, air circulating, and to prevent stagnation of the interior air. Thermal stratification is very important for efficient ventilation, fire exhaust, and solar heating. It affected by the flow and the heat transfer parameters that can be improved by controlling these parameters (Hahne \& Chen, 1998). Stratification phenomenon and stratified flow characteristics are still encountered in many applications; the flow of smoke and pollutants in a fully insulated environment often gets stratified. The prediction of stratified flow characteristics is so important for preventing and managing HVAC in buildings. Detailed computational and experimental simulations and analyses of possible scenarios are performed in order to design effective safety programs and installation of HVAC equipment. In this case, smoke and contaminated pollutants from human beings, cooking and combustion rise upward to the ceiling due to buoyancy. The indoor smoke and pollutants were accumulated in stable stratified layers near the ceiling. Therefore, it is useful to know the height, the thickness and the degree of stratification to which smoke/pollutants would rise and other stability characteristics of the stratified layers. For high indoor air quality, the smoke is removed out while the fresh air enters near the floor level and displacement ventilation flow sets in with very little mixing. The temperature gradient in a room is always positive (or zero) and increases up to the ceiling, while the contaminant concentration might have another form with a maximum somewhere in the middle of the room. The temperature gradient is very much dependent on the ventilation flow rate and not so much about the position of the heat sources (Mundt, 1995). The contaminant removal effectiveness (the system's ability to remove contaminants from the space.), in displacement ventilation, was found to be related to the ventilation flow rate, and very sensitive to the level of the source and its position (Mundt, 2001). However Hagstrom et al. (2000) found that it was a function of both the location and the power of the sources in relation to the supply and exhaust openings.

Li and Delsante (2001) and Chen and Li (2002) investigated the effect of both wind and thermal buoyancy on the position of neutral buoyancy. They used vents at multiple levels, and applied mass, energy and momentum equations. It was found that the position of neutral buoyancy can be related to the ratio of the upper and lower vent areas depending on the nature of the heat source. Mathematical and experimental investigations done by 
Hunt and Linden (1999) and Guohui Gan (2010) on the interaction between wind and buoyancy effects in natural ventilation of buildings were done to describe the natural ventilation using the combined effects of buoyancy and wind. They derived a mathematical model for stratified layer interface height based on wind speed and openings heights.

A relationship between the neutral height of air distribution and ventilation load was investigated by Xing and Awbi (2002). The results were obtained for a ventilated room, under several activities, using displacement ventilation. The analytical model calculates the temperature elevation in the room with a distributed heat flux. The position of neutral buoyancy, (the position where pressure in the room equals that in the exterior), was investigated by Andersen (2003); Li et al. (2000); Fitzgerald and Woods (2004). An analytical model was developed by Fitzgerald and Woods (2007) who studied the influence of stacks on flow patterns and stratification associated with natural ventilation with two openings. Holford and Woods (2007) used analytical models to study thermal buffering of naturally ventilated buildings through internal thermal mass. They found that the role of thermal mass in buffering the interior temperature was very different under different ventilation rates. Coffey and Hunt (2007) developed different analytical models of calculating ventilation effectiveness to evaluate mixing and displacement ventilation.

Chen and Li (2002) as Gilani et al. (2013) studied the effects of buoyancy source, opening sizes and locations of a single zone building on displacement ventilation. The investigations were for three level openings. The results showed that the ventilation mode is a function of buoyancy source and geometries. They found that the location of the stratification interface level height is a function of the geometrical parameters and independent of the strength of buoyancy source. The results of Chen and Li, (2002) we're in an agreement with Linden et al. (1990) that the stratification within a space depends on the enterainment produced by buoyancy sources upon the geometry of the sources and the openings rather than the source strength while the strength of stratification however depend on the source strength. It is also in an agreement with the work of Hunt and Linden (2001), which showed that for ventilation driven by a single localized source of buoyancy flux, a stable two-layer stratification and displacement flow forms. The steady height of the interface, between the buoyant upper layer and the lower layer at ambient density, is independent of buoyancy flux and depends only on the effective area of the openings, the height of the enclosure and air entrainment into the plume. Heat loss in solar storage tanks was basically the main (destructive) item among several loss factors, investigated by Al-Najem (1993). Al-Najem and El-Refaee (1997) did a comparison study for prediction of a turbulent mixing factor (eddy conductivity) at the inlet and outlet of a thermal storage tank, also the performance of thermal stratification in that tank. The model showed a good agreement with the experimental data of Loehke et al. (1978). The analysis of Alizadeh (1999) can be used to link the flow parameters in the stratified layer using the properties of flow in the lower and upper zones. Chena Q (2009) studied ventilation performance prediction for buildings. He presented an overview of the tools used to predict ventilation performance, such as analytical models, empirical models, small-scale experimental models, full-scale experimental models, multizone models, zonal models, and Computational Fluid Dynamics (CFD) models. Chena Q (2009) found that the analytical and empirical models had made minimal contributions to the research literature in the past year. The small- and full-scale experimental models were mainly used to generate data to validate numerical models. The CFD models were most popular and contributed to 70 percent of the literature found in this review as well as the large eddy simulation which presented to verify the numerical models and numerical methods (Bobin Wang \& Guixiang Cui, 2013).

In summary, most of the previous studies are experimental or numerical, with little analytical work available in the literature. This is due to the complexities of the problem and the large number of parameters involved. Existing correlations are based on empirical data and their validity is problem specific, thus cannot be employed. Considerable efforts were still made to seek more reliable and accurate models (Chena Q, 2009). However, simple mathematical models resulting from analytical analysis of the problem is of special significance for both

It is the objective of the present work to analytically investigate the phenomenon of stratification in a ventilated room to predict the temperature distribution at different conditions. The analytical model is derived from the fundamental equations of fluid dynamics and thermodynamics. The prediction with the developed mathematical model was conducted and comparison was made with experimental data from literature to present the similarities and differences between the experimental and analytical predictions.

\section{Theoretical Backgrounds}

Initially, we consider a simple displacement model for a chamber of height, $\mathrm{H}$ ventilated by upper and lower openings of various airflow rates. It is assumed that the Richardson number of the air within the chamber is high, such that the flow is stratified; it is further assumed that the density within the chamber varies hydrostatically 
following the Boussinesq approximation. Density differences are supposed to be small and due to temperature variations; their effect is considered only in the buoyancy terms. The concept of Archimedes, which utilizes the principle of "buoyancy", has been presented. The schematic diagram is shown in Figure (1), which shows a general representation of stratified flow of multi-layers of densities $\left(\rho_{1}, \rho_{1}^{\prime}, \rho_{1}^{\prime \prime}, \ldots, \rho_{2}^{\prime \prime}, \rho_{2}^{\prime}, \rho_{2}\right)$ and heights of $\left(h_{1}, h_{1}^{\prime}, h_{1}^{\prime \prime}, \ldots, h_{2}{ }^{\prime \prime}, h_{2}^{\prime}, h_{2}\right)$

Referring to figure (1), and by applying Archimedes conception, we have:

$$
h_{2}=\frac{\left(\rho_{1}-\rho_{2}\right)}{\rho_{1}} \frac{H}{2}
$$

Where $\mathrm{H}$ is the total height in $\mathrm{m}$.

If the density ratio $n=\frac{\rho_{1}}{\rho_{2}}$ where $\rho_{1}$ and $\rho_{2}$ espectively the density in the lower and upper layers of the flow, equation (1) becomes,

$$
\begin{aligned}
& h_{2}=\frac{(n-1)}{n} \frac{H}{2} \\
& h_{1}=\frac{1}{n} \frac{h_{2}}{2}
\end{aligned}
$$

Where, $h_{1}$ and $h_{2}$ are the heights of the lower and the upper layer respectively. From equations 2 and 3 , the new height and density ratio will be given by,

$$
\begin{aligned}
& H^{\prime}=\left[H-\left(h_{1}+h_{2}\right)\right] \\
& n^{\prime}=\frac{H}{H^{\prime}} \\
& \rho_{1}^{\prime}=n^{\prime} \rho_{2}{ }^{\prime} \\
& \rho_{2}{ }^{\prime}=\frac{\rho_{1}{ }^{\prime}}{n^{\prime}}
\end{aligned}
$$

Solving these equations from 2 to 7 , and using

$$
\frac{\rho_{1}}{\rho_{2}} \propto \frac{T_{2}}{T_{1}}
$$

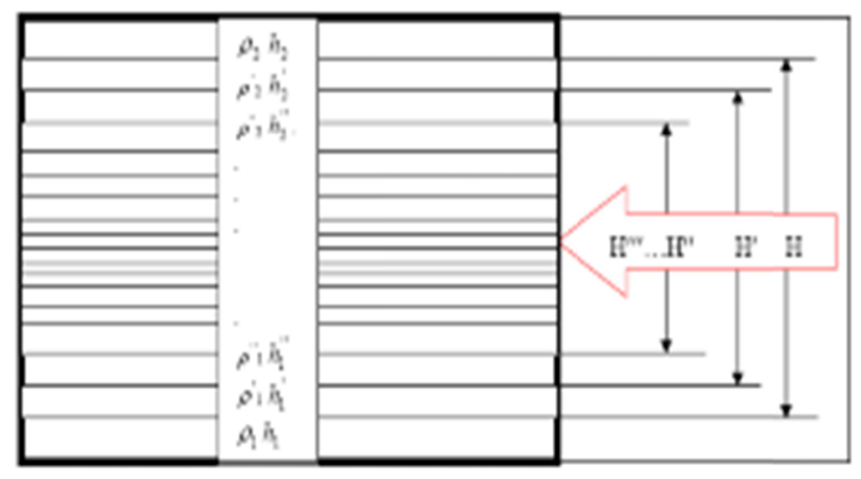

Figure 1. Schematic diagram illustrating the principle of buoyancy for multi-zone stratified flow

In order to validate the accuracy of the model, experimental results of [Awad et al. (2008)] for a stratified flow in the built environment are applied. The environmental chamber is a rectangular volume. The dimensions of the identical rectangular chamber were (7.5 m long, $3.6 \mathrm{~m}$ wide and $3.0 \mathrm{~m}$ height) with two windows (double glazed) isolated from an enclosed space. The walls of the test chamber were insulated. The walls as well as the roof were about $12.5 \mathrm{~cm}$ thick, with a white polyester outer finish and polyurethane foam interior node. The floor was a layer of light gray color of $10 \mathrm{~cm}$ thick concrete, and below it a layer of $10 \mathrm{~cm}$ thick Styrofoam. 


\section{Results and Discussion}

The mathematical model was used to solve the stratified flow, temperature distribution in a ventilated environment. The mathematical results show a good agreement for flow characteristics with the experimental results of Awad et al. (2008). The following figures show the mathematical vertical temperature profiles of air at certain typical location in the center of the environmental chamber with the two different air supply diffusers. The corresponding experimental results are also plotted in the figures as compared. The results presented were shown in Figures 2 to 7 . The flow pattern temperature profiles were selected, predicted and representative because it can represent the stratified flow characteristics in a ventilated room with an HVAC system. Figures 2, 4 and 6 show the predicted temperature profiles for various input temperatures $T_{1}$ and $T_{2}$. The vertical temperature profiles in the chamber were generally stratified. The agreement between the predicted temperature profiles and the experimental results of Awad et al. (2008) are acceptable, although discrepancies were found in these figures in some locations, because the experimental results always have some uncertainty due to slight variations in the conditions of experiments carried out. The percentage difference between the measured and predicted results ranged between (-5.5\% to $4.1 \%)$. Shown in the Figures 2,4 and 6 , the temperature gradient in the stratified region at the middle of the chamber was much larger than that in the lower and upper parts, because the stratified region stands against the flow as a buffer region between hot and cold zones where the flow was less stratified. The analysis has shown that three possible flow regimes may develop as a result of variations in the relative size of the chamber and temperature distributions as shown in the figures. Two mixed zones in the lower and upper of the chamber in between a stratified zone with high temperature gradient and different flow properties.

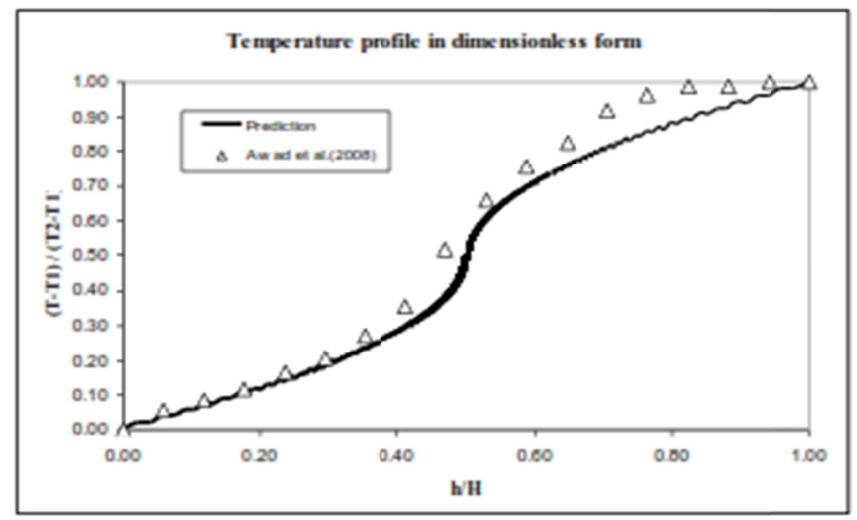

Figure 2.Vertical analytical and experimental temperature profiles for various air flow rates

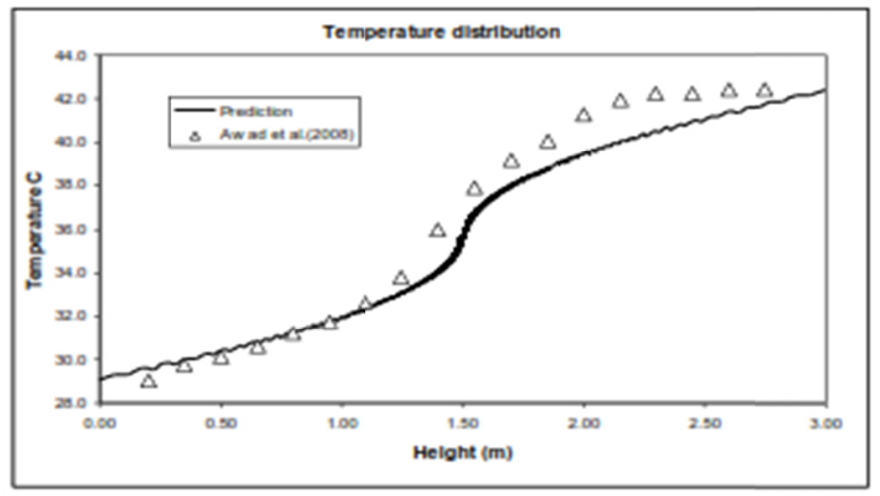

Figure 3. Vertical analytical and experimental dimensionless temperature profiles for various air flow rates centre 


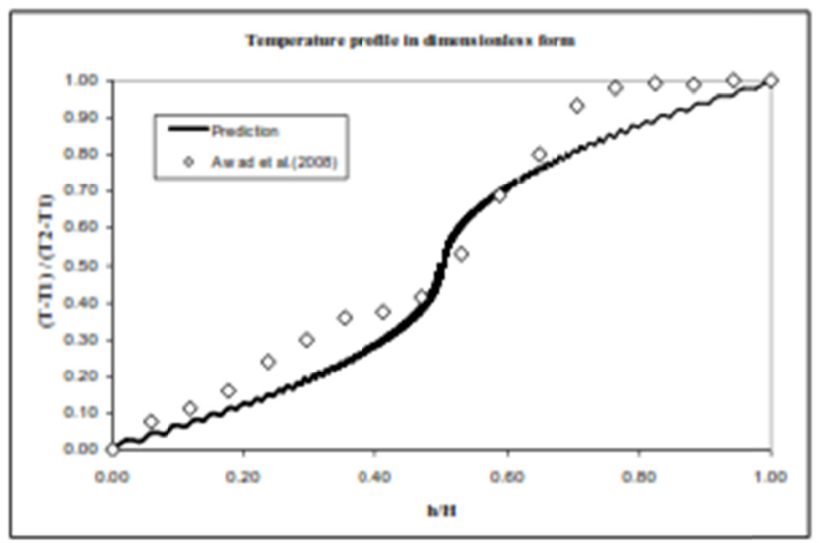

Figure 4. Vertical analytical and experimental temperature profiles for various air flow rates

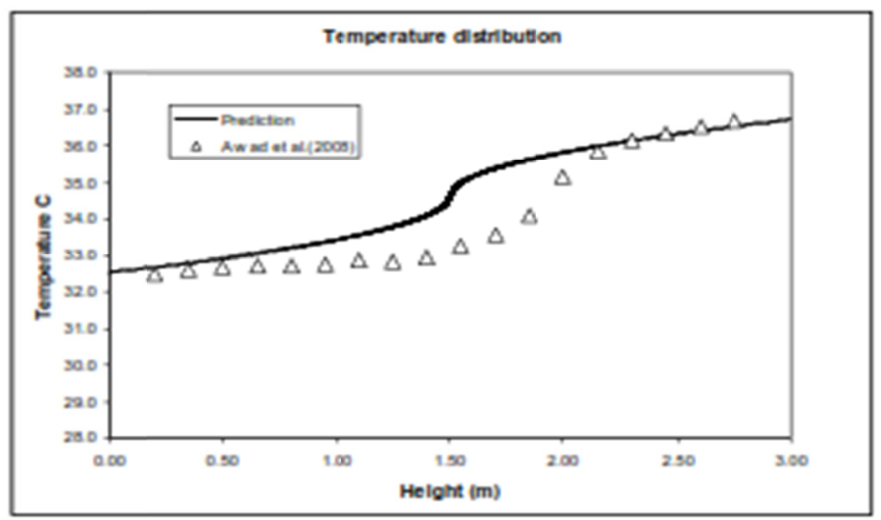

Figure 5. Vertical analytical and experimental dimensionless temperature profiles for various air flow rates

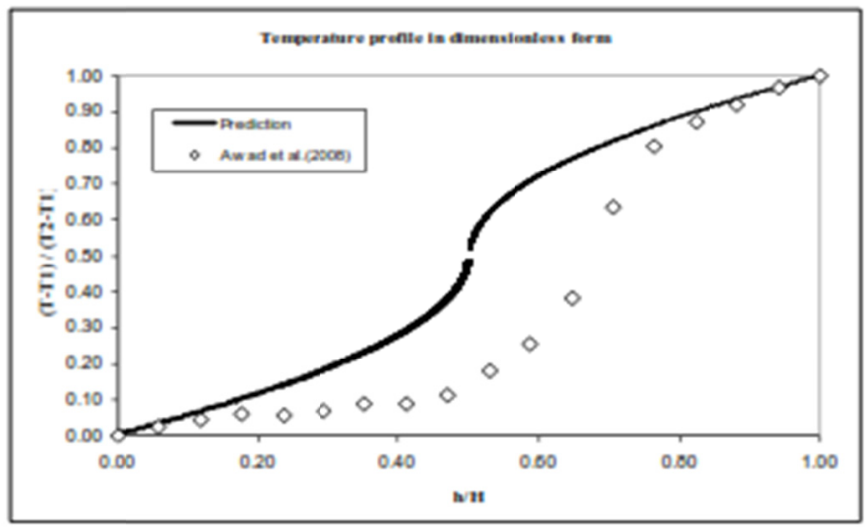

Figure 6. Vertical analytical and experimental temperature profiles for various air flow rates 


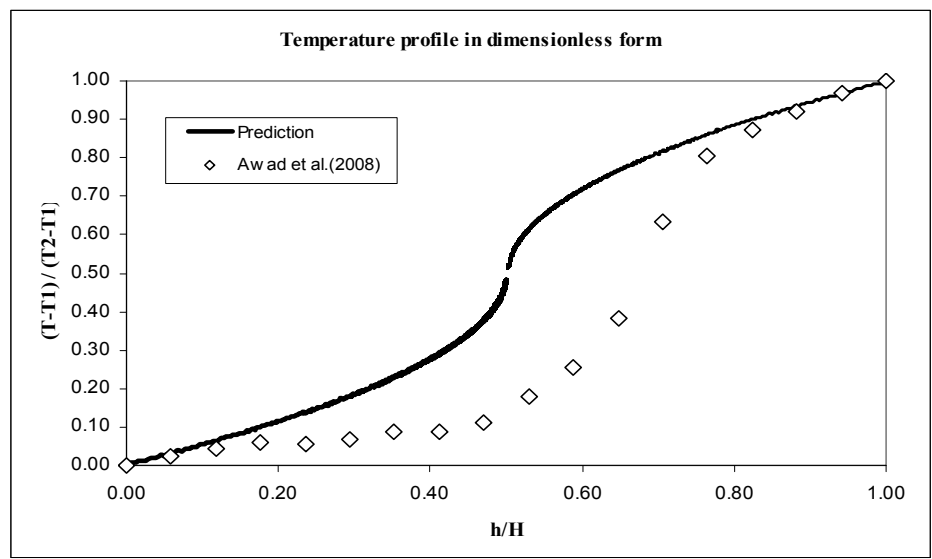

Figure 7. Vertical analytical and experimental dimensionless temperature profiles for various air flow rates

Figure 6 shows the temperature distributions predicted at $\left(\mathrm{T}_{1}=32.25{ }^{\circ} \mathrm{C}\right.$ and $\left.\mathrm{T}_{2}=36.7{ }^{\circ} \mathrm{C}\right)$. The agreement between the predicted results and measured data of [Awad et al. (2008)] is not as good as that in figures 2 and 4 were the temperature gradients are $\left(4.7{ }^{\circ} \mathrm{C} / \mathrm{m}\right.$ and $\left.4.75{ }^{\circ} \mathrm{C} / \mathrm{m}\right)$ respectively. Since the temperature gradient in figure 6 is $\left(1.5^{\circ} \mathrm{C} / \mathrm{m}\right)$ is not efficient for the flow to stratify so it is difficult to get good agreement. The percentage difference between the measured and predicted results ranged between $(-5 \%$ to $0 \%)$. Other results can be obtained by comparing the predicted observed shape of the vertical temperature profile. This is done in Figures 3, 5 and 7, which shows normalized vertical profiles of the temperature increase $\frac{T-T_{1}}{T_{2}-T_{1}}$ with the normalized height $\frac{Z}{H}$ calculated for different values input temperature difference $\left(\Delta \mathrm{T}=\mathrm{T}_{2}-\mathrm{T}_{1}\right)$. The shape of the calculated profile is sensitive to the values of input temperatures difference $\Delta \mathrm{T}$. Higher values of input $\Delta \mathrm{T}$ tend to produce large temperature gradient concentrated in the middle zone of the chamber. Lower values of $\Delta \mathrm{T}$ tend to produce low temperature gradient in both the lower and upper zones. In the lower zone it is an upwards concave profile, while in the upper zone it is a downward concave profiles whose shape we're in agreement with the experimental results of Awad et al. (2008) mainly in the lower part of the chamber. Figure 3 shows that the predicted normalized temperature is in good agreement with the measured values at all zones of the chamber. In the upper zone, it is observed that the predicted values were consistently lower than the measured values, whiles it is at the opposite in the lower zone. Compared with the results of Awad et al. (2008), the mathematical model is reasonably accurate in predicting the temperature profiles in the isolated chamber. Figures 5 and 7 show the comparison of the model predictions for high and low temperature gradients with the experimental results Awad et al. (2008), Figure 5 represents the case $\Delta \mathrm{T}=4.75^{\circ} \mathrm{C} / \mathrm{m}$ and figure 7 the case $\Delta \mathrm{T}=1.5^{\circ} \mathrm{C} / \mathrm{m}$. In the first case the flow has a stronger stratification. In the latter case, the stratified region is so small, the mixing above and below the stratified region is so high. The small temperature difference will decrease the buoyancy effect and the stability of the flow so the $\mathrm{Ri}$, which resulted in weak stratification. In both cases, the qualitative agreement is excellent and the quantitative agreement is quite reasonable, and the model slightly over predicts the temperature gradients.

\section{Conclusions}

A mathematical model based on first principles, to predict stratified flow characteristics, such as temperature distribution and temperature gradient in a ventilated environment is developed. The flow is essentially of mechanical displacement type flow leading to stratification. There is a flow parameter, the temperature distribution that depends on geometry of the chamber and needs to be obtained for different cases. Comparison of the present analytical model with the previous works shows that the model provides favorable acceptable solutions for a whole range of flow parameters and ventilation scenarios. So the mathematical model is reasonably accurate in predicting the temperature profiles in the isolated chamber. In the light of the present analytical investigations, it can be concluded that additional theoretical and experimental Information is required for a better understanding of the complex phenomena (stratification)

\section{References}

Alizadeh Sh. (1999). Experimental and numerical study of thermal stratification in a horizontal cylindrical solar storage tank. Solar Energy, 6(6), 409-421.

Al-Najem N. (1993). Degradation of stratified thermocline in solar storage tanks. Int. J. Energy Res., 17, 
183-191. http://dx.doi.org/10.1002/er.4440170306

Al-Najem, N. M., \& El-Refaee, M. M. (1997). A numerical study for the prediction of turbulent mixing factor in thermal storage tanks. Applied Thermal Engineering, 17(12), 1173-1181. http://dx.doi.org/10.1016/S1359-4311(97)00030-6

Andersen K. T. (2003). Theory for natural ventilation by thermal buoyancy in one zone with uniform $\begin{array}{llll}\text { temperature, } \quad \text { Building } & \text { and }\end{array}$ http://dx.doi.org/10.1016/S0360-1323(03)00132-X

Awad A. S., Badran, O. O., Holdo, E., \& Calay, R. (2008). The Effect of ventilation aperture location of input airflow rates on the stratified flow. Energy conversion and management, 49(11), 3253-3258. http://dx.doi.org/10.1016/j.enconman.2008.05.004

Bobin Wang B., \& Cui, G. (2013). Large Eddy Simulation of Unstably Stratified Turbulent Flow over Urban-Like Building Arrays. Journal of Applied Mathematics, 10.

Chen, Z. D., \& Li, Y. (2002). Buoyancy-driven displacement natural ventilation in a single-zone building with three-level openings. Building and Environment, 37(3), 295-303. http://dx.doi.org/10.1016/S0360-1323(01)00021-X

Chena Qingyan. (2009). Ventilation performance prediction for buildings: A method overview and recent applications. Building and Environment, 44(4), 848-858. http://dx.doi.org/10.1016/j.buildenv.2008.05.025

Coffey, C. J., \& Hunt, G. R. (2007). Ventilation effectiveness measures based on heat removal: Part 2, Application to natural ventilation flows. Building and Environment, 42(6), 2249-2262. http://dx.doi.org/10.1016/j.buildenv.2006.03.015

Fitzgerald, Sh. D., \& Woods, A. W. (2004). Natural ventilation of a room with vents at multiple levels. Building and Environment, 39(5), 505-521. http://dx.doi.org/10.1016/j.buildenv.2003.11.003

Fitzgerald, Sh. D., \& Woods, A. W. (2007). The influence of stacks on flow patterns and stratification associated with natural ventilation. Building and Environment, 43, 1719-1733. http://dx.doi.org/10.1016/j.buildenv.2007.10.021

Gan G. (2010). Interaction Between Wind and Buoyancy Effects in Natural Ventilation of Buildings. The Open Construction and Building Technology Journal, 4, 134-145.

Gilani S., Montazeri H., \& Blocken B. (2013). CFD Simulation of Temperature Stratification for a Building Space: Validation and Sensitivity Analysis. Proceedings of BS2013: 13th Conference of International Building Performance Simulation Association, Chambéry, France, August 26-28.

Hagström K., Sandberg E., Koskela H., \& Hautalampi T. (2000). Classification for the room air conditioning strategies. Building and Environment, 35(8), 699-707. http://dx.doi.org/10.1016/S0360-1323(99)00057-8

Hahne, E., \& Chen, Y. (1998). Numerical study of flow and heat transfer characteristics in hot water stores. Solar Energy, 64(1-3), 9-18. http://dx.doi.org/10.1016/S0038-092X(98)00051-6

Holford, J. M., \& Woods, A. W. (2007). On the thermal buffering of naturally ventilated buildings through internal thermal mass. Journal of Fluid Mechanics, 580, 3-29. http://dx.doi.org/10.1017/S0022112007005320

Hunt G. R., \& Linden, P. F. (2001). Steady-state flows in an enclosure ventilated by buoyancy forces assisted by wind. J. Fluid Mech., 426, 355-386.

Hunt, G. R., \& Linden, P. F. (1999). The fluid mechanics of natural ventilation-displacement ventilation by buoyancy-driven flows assisted by wind. Building and Environment, 34(6), 707-720. http://dx.doi.org/10.1016/S0360-1323(98)00053-5

Li, Y., \& Delsante, A. (2001). Natural ventilation induced by combined wind and thermal forces. Building and Environment, 36(1), 59-71. http://dx.doi.org/10.1016/S0360-1323(99)00070-0

Li, Y., Delsante, A., \& Symons, J. (2000). Prediction of natural ventilation in buildings with large openings. Building and Environment, 35(3), 191-206. http://dx.doi.org/10.1016/S0360-1323(99)00011-6

Linden, P. F., Lane-Serff G. F., \& Smeed, D. A. (1990). Emptying filling boxes: the fluid mechanics of natural ventilation. Journal of Fluid Mechanics, 212, 309-335. http://dx.doi.org/10.1017/S0022112090001987

Loehke, R., Gari, H., Sharp, M., \& Haberstroh, R. (1978). A passive technique for enhancing thermal stratification in liquid storage tanks, ASME, Paper No 78-HT-50. 
Mundt El. (1995). Displacement ventilation systems- Convection flow and temperature gradients. Building and Environment, 30(1), 129-133. http://dx.doi.org/10.1016/0360-1323(94)E0002-9

Mundt, E. (2001). Non-buoyant pollutant sources and particles in displacement ventilation. Building and Environment, 36(7), 829-836. http://dx.doi.org/10.1016/S0360-1323(01)00008-7

Xing, H., \& Awbi, H. B. (2002). Measurement and calculation of the neutral height in a room with displacement ventilation. Building and Environment, 37(10), 961-967. http://dx.doi.org/10.1016/j.buildenv.2005.07.013

\section{Copyrights}

Copyright for this article is retained by the author(s), with first publication rights granted to the journal.

This is an open-access article distributed under the terms and conditions of the Creative Commons Attribution license (http://creativecommons.org/licenses/by/3.0/). 